\title{
Plastin3 is associated with epithelial-mesenchymal transition and poor prognosis in gastric cancer
}

\author{
JUNJI KURASHIGE ${ }^{1,2}$, TAKEHIRO YOKOBORI ${ }^{1,3}$, KOSUKE MIMA ${ }^{1,2}$, GENTA SAWADA ${ }^{1}$, YUSUKE TAKAHASHI ${ }^{1}$, \\ HIROKI UEO $^{1}$, YUKI TAKANO ${ }^{1}$, TAE MATSUMURA ${ }^{1}$, RYUTARO UCHI $^{1}$, HIDETOSHI EGUCHI ${ }^{1}$, \\ TOMOYA SUDO ${ }^{1}$, KEISHI SUGIMACHI ${ }^{1}$, MASAKI MORI ${ }^{4}$, HIDEO BABA $^{2}$ and KOSHI MIMORI ${ }^{1}$ \\ ${ }^{1}$ Department of Surgery, Kyushu University Beppu Hospital, Beppu, Oita 874-0838; \\ ${ }^{2}$ Department of Gastroenterological Surgery, Graduate School of Medical Sciences, Kumamoto University, \\ Kumamoto 860-8556; ${ }^{3}$ Department of General Surgical Science, Graduate School of Medicine, \\ Gunma University, Maebashi, Gunma 371-8511; ${ }^{4}$ Department of Gastroenterological Surgery, \\ Osaka University Graduate School of Medicine, Suita, Osaka 565-0871, Japan
}

Received December 12, 2016; Accepted December 4, 2018

DOI: $10.3892 / \mathrm{ol} .2018 .9819$

\begin{abstract}
The plastin3 (PLS3) gene, which encodes an actin bundling protein known to inhibit cofilin-mediated depolymerization of actin fiber, has been previously reported to serve an important role in the epithelial-mesenchymal transition (EMT) in cancer. The aim of the present study was to determine the clinical significance of PLS3 and its role in regulating EMT, as well as in promoting cell invasion and migration in gastric cancer. The expression of plastin 3 mRNA was measured in 163 resected gastric cancer specimens, in order to determine the clinicopathological significance. Furthermore, in vitro invasion and migration assays were performed on gastric cancer cells, which revealed that $P L S 3$ expression was suppressed. The high PLS3 expression group had a higher incidence of advanced tumour stage, cancer differentiation, tumour invasion depth and distant metastases compared with the low PLS3 expression group $(\mathrm{P}<0.05)$. In addition, the high $P L S 3$ expression group had a significantly poorer prognosis than the low expression group $(\mathrm{P}=0.012)$. Multivariate analysis indicated that high $P L S 3$ expression was an independent prognostic factor for survival. The present study also identified that suppression of $P L S 3$ in gastric cancer cells was associated with
\end{abstract}

Correspondence to: Professor Koshi Mimori, Department of Surgery, Kyushu University Beppu Hospital, 4546 Tsurumihara, Beppu, Oita 874-0838, Japan

E-mail:kmimori@beppu.kyushu-u.ac.jp

Abbreviations: EMT, epithelial-mesenchymal transition; PLS3, plastin3; $C D H 1$, Cadherin1; RT-qPCR, reverse transcriptionquantitative polymerase chain reaction; siRNA, small interfering RNA; OS, overall survival; HR, hazard ratio; CI, confidence interval

Key words: PLS3, EMT, gastric cancer decreased cell invasion and migration. The findings from the present study indicate that high expression of $P L S 3$ in gastric cancer is independently associated with a poor prognosis, and that PL3 serves an important role in EMT.

\section{Introduction}

Gastric cancer is one of the most common types of malignancy globally (1). Improvements in diagnosis and treatment have resulted in greater long-term survival for patients with early gastric cancer; however, the prognosis for patients with advanced gastric cancer remains relatively poor, with locally advanced and widespread metastatic disease associated with a high mortality rate (2). Despite the need for an improved understanding on how gastric cancer metastasizes, the mechanisms underlying gastric cancer progression remain unclear.

Gastric cancer has the ability to spread locally via direct invasion through the gastric wall into adjacent tissue; it then has the ability to metastasize to regional lymph nodes and distant organs through the lymphatic and venous vessels. Recent evidence has emerged suggesting that acquisition of invasiveness in cancer cells is accompanied by the loss of epithelial features and the gain of a mesenchymal phenotype, in a process termed the epithelial-mesenchymal transition (EMT) (3).

A variety of molecules have been identified in tumor samples as EMT-associated markers, including the epithelial marker E-cadherin (4) and the mesenchymal marker Vimentin (5). Transcriptional factors, including the zinc-finger protein Snail (6), the basic helix-loop-helix protein Twist (7) and the E-box-binding protein ZEB1/2 $(8,9)$, are also involved in regulating EMT-associated changes. It has been previously reported that matrix metalloproteinases serve key roles in the invasion and metastasis of gastric cancer (10-13).

Expression of the actin-binding protein L-plastin in SW480 cells was recently demonstrated to cause a downregulation of E-cadherin and an increase in invasiveness (14). Furthermore, it was previously reported that the Plastin3 
(PLS3) gene, which is known to code for an actin bundling protein that inhibits cofilin-mediated depolymerization of actin, may be used as a marker for circulating tumor cells; $P L S 3$ has been demonstrated to serve an important role in the EMT of colorectal carcinoma cells (15). However, there are few reports to data regarding the clinical significance of PLS3 in epithelial malignancies.

In the present study, the clinical significance of PLS3 in gastric cancer was identified as an independent prognostic factor and the association between the EMT markers Cadherin 1 (CDH1), Vimentin and PLS3 was indicated. Furthermore, it was demonstrated in an in vitro study that PLS3 serves a key role in invasion and migration in gastric cancer.

\section{Materials and methods}

Clinical samples and cell lines. Primary gastric carcinoma and adjacent normal gastric epithelial tissues were obtained from a total of 163 patients who underwent gastric resection, without preoperative treatment, at The Oita Prefectural Hospital (Oita, Japan) or The Kyushu University Beppu Hospital (Beppu, Japan) between 1993 April and 2003 December. All of the obtained tissue samples were cut and immediately placed into RNAlater ${ }^{\circledR}$ (Takara Bio, Inc., Otsu, Japan), then frozen in liquid nitrogen and kept at $-80^{\circ} \mathrm{C}$ until RNA extraction. Written informed consent was obtained from all of the patients and the protocol of the study was approved by the Ethics Committee of Kyushu University (Fukuoka, Japan). Clinicopathological information, including age (range, 40-87 years), sex, pathology, differentiation and tumor-node metastasis classification, was available for all patients. The tumor size was calculated under the microscope by pathologists. The median overall survival (OS) time was 32 months and ranged from 1-144 months.

Human gastric cancer cell lines NUGC3, NUGC4, MKN7, MKN45, MKN74 and AGS were provided by the Cell Resource Centre for Biomedical Research Institute of Development, Aging and Cancer, Tohoku University (Sendai, Japan). All cells were grown in RPMI-1640 medium (Cambrex Corporation, East Rutherford, NJ, USA), supplemented with $10 \%$ foetal bovine serum (Sigma-Aldrich; Merck KGaA, Darmstadt, Germany), 2 mmol/l glutamine, $100 \mathrm{U} / \mathrm{ml}$ penicillin and $100 \mu \mathrm{g} / \mathrm{ml}$ streptomycin (Cambrex Corporation); this was followed by incubation at $37^{\circ} \mathrm{C}$ in a humidified chamber with $5 \% \mathrm{CO}_{2}$.

Immunohistochemistry. Immunohistochemical studies of PLS3 were performed on formalin-fixed paraffin-embedded surgical sections (5- $\mu \mathrm{m}$ thick) obtained from 43 patients with gastric cancer treated at the Kyushu University Beppu Hospital (Beppu, Japan). Tissue sections were deparaffinised and boiled in $0.01 \mathrm{~mol} / 1$ sodium citrate buffer $(\mathrm{pH} \mathrm{9.0;0.01} \mathrm{ml}$ of $1 \mathrm{M}$ disodium citrate and $99.99 \mathrm{ml}$ of $1 \mathrm{M}$ trisodium citrate) in a microwave for $10 \mathrm{~min}$ at $500 \mathrm{~W}$ for antigen retrieval and then washed in phosphate-buffered saline (PBS). The primary antibody used was goat anti-PLS3 (C15; cat no. sc-16555; Santa Cruz Biotechnology, Inc., Dallas, TX, USA), which was diluted to a ratio of 1:100 and incubated with the slides for $15 \mathrm{~min}$ at room temperature. All tissue sections were immunohistochemically stained with the avidin-biotin-peroxidase LASB2 kit (cat. no. K0675; Dako; Agilent Technologies, Inc.,
Santa Clara, CA, USA) according to the protocol of the manufacturer, and were counterstained with haematoxylin at room temperature for $3 \mathrm{~min}$. Representative photomicrographs were captured with a Nikon Eclipse E800 microscope equipped with a Nikon DXM1200 digital camera (Nikon instruments, Melville, NY, USA). Slides were observed under light microscopy at x40 magnification, and five regions were selected for every slide at random. The degree of differentiation was independently evaluated by two of the authors (Dr Junji Kurashige and Dr Kosuke Mima) using a blinded protocol design, with the observers having no knowledge of the clinical outcome or any other clinicopathological data. For evaluation of the PLS3 expression, the staining intensity was scored as 0 (negative), 1 (weak), 2 (medium) or 3 (strong) as previously indicated (16).

Total RNA isolation and first-strand cDNA synthesis. Total RNA was isolated from frozen tissue samples and cultured cell lines using a modified acid-guanidine-phenol-chloroform method as described previously (15). The purity and concentration of all RNA samples were evaluated using an absorbance ratio of 260/280 nm with a NanoDrop ${ }^{\mathrm{TM}} \mathrm{ND}-1000$ spectrophotometer (NanoDrop Technologies; Thermo Fisher Scientific, Inc., Waltham, MA, USA). Total RNA was reverse transcribed with M-MLV RT, according to the manufacturer's protocol (Invitrogen; Thermo Fisher Scientific, Inc.).

Reverse transcription-quantitative polymerase chain reaction (RT-qPCR). The expression levels of PLS3, CDH1 and Vimentin were determined using a LightCycler ${ }^{\circledR} 480$ Probes Master kit (Roche Molecular Diagnostics, Pleasanton, CA, USA), according to the manufacturer's instructions. The primer sequences used in RT-qPCR were as follows: PLS3 forward 5'-GAA ACTTACACCCTTCATCAT TCAG-3', reverse 5'-TTCTGCACCAATGTTCACAAC-3' and universal probe no. 29; $C D H 1$ forward 5'-GGCCAGGAAATCACA TCCTA-3', reverse 5'-GGCAGTGTCTCTCCAAATCC-3' and universal probe no. 36; Vimentin forward 5'-TACAGGAAG CTGCTGGAAGG-3', reverse 5'-ACCAGAGGGAGTGAAT CCAG-3' and universal probe no. 13; GAPDH forward 5'-AGC CACATGCTCAGACAC-3', reverse 5'-AATACGACCAAA TCCGTTGACT-3' and universal probe no. 60. All RT-qPCR reactions were run in a LightCycler ${ }^{\circledR} 480$ system II (Roche Molecular Diagnostics). The relative amounts of $\mathrm{PLS3}, \mathrm{CDH} 1$ and Vimentin were measured using the $2^{-\Delta \Delta \mathrm{Cq}}$ method (17) and normalized to GAPDH. All RT-qPCR reactions were performed in triplicate.

PLS3 RNA interference. Small interfering RNAs (siRNA) against $P L S 3$ no. 1 (5'-CAGCAACGGAUUCAUUUGUTT-3') and 2 (5'-CUGCUUAGAUGGGCAAACUTT-3'), along with control non-targeting siRNA were obtained from Ambion (Thermo Fisher Scientific, Inc.). The non-silencing control siRNA, which has no sequence homology to any known human gene sequence, was used as a control with non-specific effects for all experiments. The siRNA oligomer was diluted with Opti-MEM I without serum (Invitrogen; Thermo Fisher Scientific, Inc.). The diluted siRNA oligomer was mixed with diluted Lipofectamine ${ }^{\circledR}$ RNAiMAX (Invitrogen; Thermo Fisher Scientific, Inc.), and incubated for $15 \mathrm{~min}$ at room temperature to allow siRNA-Lipofectamine ${ }^{\circledR}$ RNAiMAX 
complexes to form. The optimal amount of siRNA used for transfection was determined to be $20 \mathrm{nmol} / \mathrm{l}$. Diluted logarithmic growth phase NUGC3 and AGS cells without antibiotics were seeded at a density of $2 \times 10^{5}$ cells/well in a final volume of $2.5 \mathrm{ml}$ into 6 -well flat-bottom microtiter plates. The cells were incubated in a humidified atmosphere $\left(37^{\circ} \mathrm{C}\right.$ and $5 \% \mathrm{CO}_{2}$ ). The assay was performed after a $72-\mathrm{h}$ incubation.

Migration and invasion assay. Cell migration was assessed using The BD Falcon ${ }^{\mathrm{TM}}$ FluoroBlok $^{\mathrm{TM}} 24$ Multiwell Insert $^{2}$ system (BD Bioscience, San Jose, CA, USA). For a period of $24 \mathrm{~h}$ prior to the assay, cells were transfected with PLS3 siRNA or a negative control siRNA. The NUGC3 and AGS cells $\left(1.0 \times 10^{4}\right)$ were placed in the upper chamber of a 24 -well plate with serum-free RPMI-1640 medium. The lower chamber was filled with $750 \mu \mathrm{l}$ medium with $10 \%$ foetal bovine serum, in which the serum acted as a chemoattractant, and the cell migration plate was incubated in a humidified atmosphere $\left(37^{\circ} \mathrm{C}\right.$ and $5 \% \mathrm{CO}_{2}$ ). After a $48 \mathrm{~h}$ incubation, the upper chamber was transferred into a second 24-well plate containing $500 \mu \mathrm{l} /$ well of $4 \mu \mathrm{g} / \mathrm{ml}$ calcein AM in HBSS (Invitrogen; Thermo Fisher Scientific, Inc.) and incubated for $1 \mathrm{~h}\left(37^{\circ} \mathrm{C}\right.$ and $\left.5 \% \mathrm{CO}_{2}\right)$. Invasive cells that migrated through the membrane were evaluated using a fluorescence plate reader at excitation/emission wavelengths of 485/535 $\mathrm{nm}$. Each independent experiment was performed three times. NUGC3 cell invasion was assessed using the BD BioCoat ${ }^{\mathrm{TM}}$ Tumor Invasion system 24-Multiwell (BD Bioscience, San Jose, CA, USA) and the same procedure as that used for migration.

Statistical analysis. All experiments were performed $\geq 3$. Continuous variables were expressed as the mean \pm standard deviation. The association between the expression of PLS3 and the patient clinicopathological characteristics was analysed using a Student's t-test or $\chi^{2}$ analysis. The OS time curves were plotted according to the Kaplan-Meier method and the generalized log-rank test was applied to compare the survival curves. $\mathrm{P}<0.05$ was considered to indicate a statistically significant difference. All tests were performed using JMP ${ }^{\circledR}$ software 8th edition (SAS Institute, Inc., Cary, NC, USA).

\section{Results}

Immunohistochemistry of PLS3 expression. Expression of the PLS3 protein was evaluated by immunohistochemical analysis of resected gastric cancer specimens using the anti-PLS3 antibody. PLS3 staining was notably strong in poorly differentiated gastric cancer tissues (Fig. 1A) and in the budding foci in well differentiated gastric cancer (Fig. 1B). On the other hand, PLS3 staining was weak in differentiated gastric cancer tissues (Fig. 1C). Overall, the staining was primarily located within the cytoplasm.

PLS3 mRNA expression and clinicopathological characteristics. Expression levels of PLS3 were examined in 163 gastric cancer clinical samples using RT-qPCR, with quantified values used to calculate $P L S 3 / G A P D H$ ratios. In the specimens with strong staining, the mRNA expression levels of PLS3 were significantly higher compared with that in the weak staining group $(\mathrm{P}<0.05$; Fig. 1D). The 163 patients with
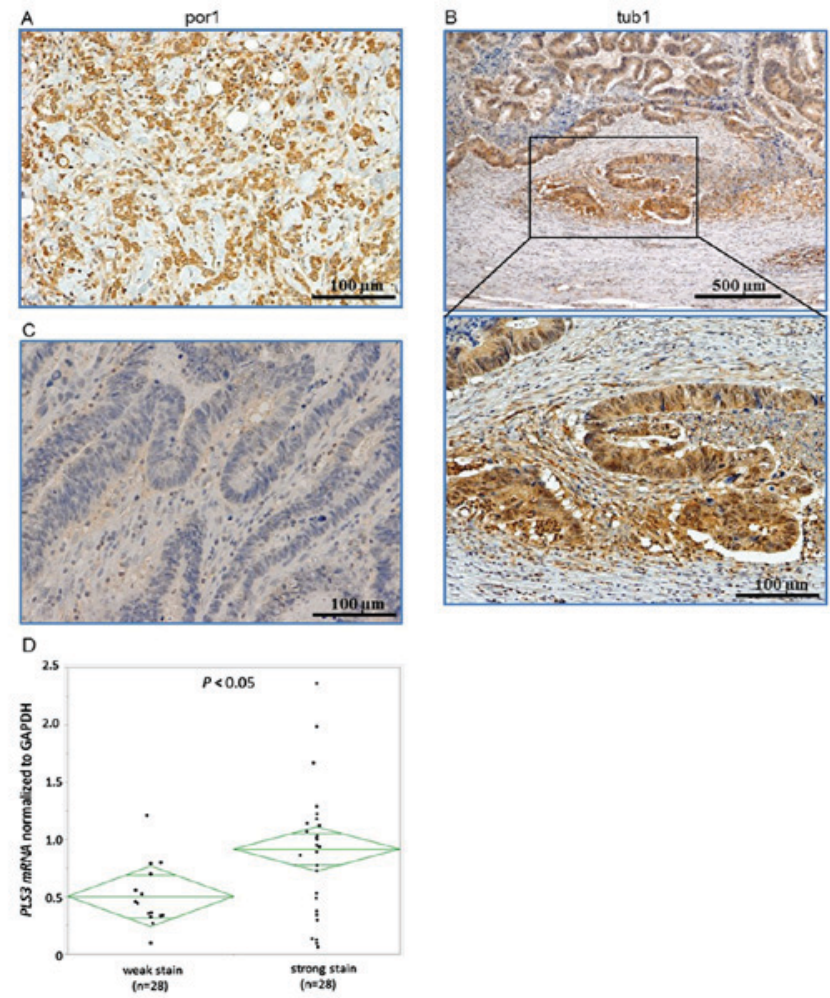

Figure 1. PLS3 expression in representative samples of gastric cancer The majority of staining in the cancer cells was located in the cytoplasm. (A) PLS3 staining was strong in poorly differentiated gastric cancer tissues (x40 magnification) and (B) in budding foci in well differentiated gastric cancer (top panel, x40 magnification; bottom panel, x200 magnification). (C) PLS3 staining was weak in differentiated gastric cancer tissues (x200 magnification). (D) In the strong staining specimens, the mRNA expression levels of $P L S 3$ were significantly higher than in the weak staining group. $P L S 3$, plastin3; por1, porin 1; tub1, $\alpha$-tubulin 1 .

gastric cancer were divided into two groups according to the median PLS3 mRNA expression level: 82 of the cases were placed in the high PLS3 expression group, and the remaining 81 cases were placed into the low $P L S 3$ expression group. The association between patient clinicopathological characteristics and PLS3 expression is summarized in Table I. PLS3 expression was significantly associated with cancer differentiation (well and moderately differentiated vs. poorly differentiated and others; $\mathrm{P}=0.010$ ), depth of tumour invasion (T1 and T2 vs. $\mathrm{T} 3$ and $\mathrm{T} 4 ; \mathrm{P}=0.029$ ), distant metastasis (present vs. absent; $\mathrm{P}=0.010$ ) and cancer staging (stage I and II vs. III and IV; $\mathrm{P}=0.002)$. By contrast, there was no significant association between $P L S 3$ expression and age $(\mathrm{P}=0.143)$, sex $(\mathrm{P}=0.953)$, lymph node metastasis (present vs. absent; $\mathrm{P}=0.825$ ), venous invasion (present vs. absent; $\mathrm{P}=0.788$ ) and peritoneal metastasis (present vs. absent; $\mathrm{P}=0.900$ ).

Survival analysis for the expression of PLS3. Analysis of the 5-year OS revealed that the high PLS3 expression group had a significantly poorer prognosis compared with the low expression group ( $\mathrm{P}=0.012$; Fig. 2). In a univariate Cox regression analysis, the high $P L S 3$ expression group displayed significantly higher overall mortality [hazard ratio (HR), 2.211; 95\% confidence interval (CI), 1.299-3.764; $\mathrm{P}=0.012$; Table II] compared with the low PLS3 expression group. Variables with $\mathrm{P}<0.05$ from univariate analysis were selected for multivariate 
Table I. PLS3 mRNA expression and clinicopathological features.

PLS3 mRNA expression

\begin{tabular}{|c|c|c|c|c|}
\hline & & & & \\
\hline Features & Total $(n=163)$ & High $(n=82)(\%)$ & Low $(\mathrm{n}=81)(\%)$ & P-value \\
\hline Age (years) & & & & 0.143 \\
\hline Mean \pm SD & $65.9 \pm 11.2$ & $64.6 \pm 10.9$ & $67.2 \pm 11.9$ & \\
\hline Sex & & & & 0.953 \\
\hline Male & 105 & $53(64.6)$ & $52(64.2)$ & \\
\hline Female & 58 & $29(35.4)$ & $29(35.8)$ & \\
\hline Differentiation & & & & $0.010^{\mathrm{a}}$ \\
\hline Well/moderately & 76 & $30(36.6)$ & $46(56.8)$ & \\
\hline Poorly/others & 87 & $52(63.4)$ & $35(43.2)$ & \\
\hline Depth of tumor invasion & & & & $0.029^{\mathrm{a}}$ \\
\hline $\mathrm{T} 1-2$ & 59 & $23(28.0)$ & $36(44.4)$ & \\
\hline T3-4 & 104 & $59(72.0)$ & $45(55.6)$ & \\
\hline Lymph node metastasis & & & & 0.825 \\
\hline Absent & 57 & $28(34.1)$ & $29(35.8)$ & \\
\hline Present & 106 & $54(65.9)$ & $52(64.2)$ & \\
\hline Lymphatic invasion & & & & 0.788 \\
\hline Absent & 58 & $30(36.6)$ & $28(34.6)$ & \\
\hline Present & 105 & $52(63.4)$ & $53(65.4)$ & \\
\hline Venous invasion & & & & 0.900 \\
\hline Absent & 120 & $60(73.2)$ & $60(74.1)$ & \\
\hline Present & 43 & $22(26.8)$ & $21(25.9)$ & \\
\hline Peritoneal metastasis & & & & 0.806 \\
\hline Absent & 138 & $69(84.1)$ & $67(82.7)$ & \\
\hline Present & 27 & $13(15.9)$ & $14(17.3)$ & \\
\hline Distant metastasis & & & & $0.010^{\mathrm{a}}$ \\
\hline Absent & 150 & $71(86.6)$ & $79(97.5)$ & \\
\hline Present & 13 & $11(13.4)$ & $2(2.5)$ & \\
\hline Stage & & & & $0.002^{\mathrm{a}}$ \\
\hline I-II & 93 & $37(45.1)$ & $56(69.1)$ & \\
\hline III-IV & 70 & $45(54.9)$ & $25(30.9)$ & \\
\hline
\end{tabular}

${ }^{\mathrm{a}} \mathrm{P}<0.05$. Staging was classified by Union for International Cancer Control 7th edition system (20). mRNA, messenger RNA; T, tumour; SD, standard deviation; PLS3, Plastin3.

analysis with the Cox's proportional hazard model. In a multivariate Cox regression analysis for OS time, including tumour depth, tumour size, lymph node metastasis, venous invasion, peritoneal metastasis and PLS3 expression, high PLS3 expression was indicated to be an independent prognostic factor $(\mathrm{HR}$, 1.770; 95\% CI, 1.020-3.074; P=0.042; Table II).

Inhibition of PLS3 gene expression with PLS3 siRNA in human gastric cancer cells. Knockdown of PLS3 mRNA was performed in NUGC3 and AGS gastric cancer cells, which have the highest PLS3 mRNA expression levels among eight different gastric cancer cell lines examined (NUGC3, NUGC4, MKN7, MKN45, MKN74, AGS) (data not shown). Evaluation of the expression levels following PLS3 siRNA transfection confirmed that PLS3 mRNA expression in cells transfected with PLS3 siRNA no. 1 and 2 was lower compared with that in cells transfected with the negative control siRNA (Fig. 3A). The transfected cells were used to investigate whether PLS3 knockdown altered migration and invasion. NUGC3 and AGS cells transfected with PLS3 siRNA exhibited reduced migratory abilities $(\mathrm{P}<0.05$; Fig. $3 \mathrm{~B})$, and NUGC cells were significantly less invasive $(\mathrm{P}<0.05$; Fig. $3 \mathrm{C})$, compared with those cells transfected with the negative control siRNA. These results indicate that knockdown of PLS3 suppressed the migration and invasion of gastric cancer cells in vitro.

Association between $C D H 1$ and Vimentin mRNA expression, and PLS3 mRNA expression in gastric cancer. The association between the expression of PLS3, and that of $C D H 1$ and Vimentin in patients with gastric cancer was investigated. The 163 gastric cancer cases were classified into high and low expression groups, according to the median PLS3 mRNA 
Table II. Univariate and multivariate analysis of clinicopathological features for 5-year OS (Cox's proportional regression model).

\begin{tabular}{|c|c|c|c|c|c|c|}
\hline \multirow[b]{2}{*}{ Features } & \multicolumn{3}{|c|}{ Univariate analysis } & \multicolumn{3}{|c|}{ Multivariate analysis } \\
\hline & HR & $95 \% \mathrm{CI}$ & P-value & HR & $95 \% \mathrm{CI}$ & P-value \\
\hline Age years $(>65 / 65 \geq)$ & 0.765 & $0.460-1.272$ & 0.301 & & & \\
\hline Sex (male/female) & 0.893 & $0.513-1.553$ & 0.688 & & & \\
\hline Differentiation (well, moderate/poor, other) & 1.375 & $0.820-2.305$ & 0.228 & & & \\
\hline $\mathrm{T}(1,2 / 3,4)$ & 3.239 & $1.681-3.514$ & $<0.001^{\mathrm{a}}$ & 1.301 & $0.575-2.944$ & 0.577 \\
\hline Tumor size $(<50 / \geq 50 \mathrm{~mm})$ & 2.068 & $1.225-3.490$ & $0.007^{\mathrm{a}}$ & 0.835 & $0.445-1.570$ & 0.527 \\
\hline Lymph node metastasis (absent/present) & 4.387 & $2.149-8.958$ & $<0.001^{\mathrm{a}}$ & 2.876 & $1.318-6.274$ & $0.008^{\mathrm{a}}$ \\
\hline Venous invasion (absent/present) & 3.386 & $2.013-5.696$ & $<0.001^{\mathrm{a}}$ & 1.734 & $0.975-3.086$ & $0.061^{\mathrm{a}}$ \\
\hline Lymphatic invasion (absent/present) & 3.748 & $1.835-7.656$ & $<0.001^{\mathrm{a}}$ & & & \\
\hline Peritoneal metastasis (absent/present) & 6.644 & $3.706-11.912$ & $<0.001^{\mathrm{a}}$ & 3.553 & $1.873-6.740$ & $<0.001^{\mathrm{a}}$ \\
\hline Stage (I,II/III,IV) & 5.460 & $3.096-9.629$ & $<0.001^{\mathrm{a}}$ & & & \\
\hline PLS3 expression (low/high) & 2.211 & $1.299-3.764$ & $0.012^{\mathrm{a}}$ & 1.770 & $1.020-3.074$ & $0.042^{\mathrm{a}}$ \\
\hline
\end{tabular}

${ }^{\text {a }}<0.05$; HR, hazard ratio; CI, confidence interval; T, tumor; OS, overall survival; PLS3, Plastin3.

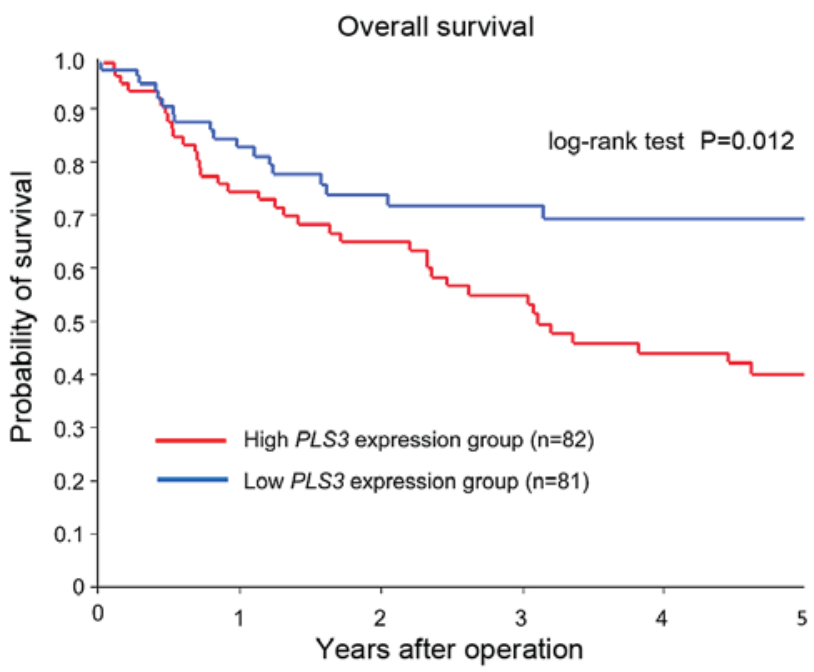

Figure 2. Kaplan-Meier survival curves of high and low PLS3 expression groups. A total of 163 gastric cancer cases were classified into two groups according to the median PLS3 mRNA expression level determined by reverse transcriptase-quantitative polymerase chain reaction. The high expression group consists of 82 patients, with the low expression group containing 81 . The OS time of patients with gastric cancer in each group is depicted according to the level of PLS3 mRNA expression. The survival rate for patients in the high $P L S 3$ expression group was significantly lower than that for patients in the low expression group $(\mathrm{P}=0.012)$. PLS3, plastin3; OS, overall survival.

expression levels determined by RT-qPCR. As presented in Fig. 4A, Vimentin mRNA expression levels were significantly increased in the high PLS3 expression group $(\mathrm{n}=82)$, compared within the low $P L S 3$ expression group $(\mathrm{n}=81 ; \mathrm{P}<0.01)$; however, there was no significant difference in $C D H 1$ mRNA expression between the high and low PLS3 expression groups. Similarly, Vimentin mRNA was significantly decreased in NUGC3 cells transfected with siRNA no. 1 and 2, compared with the negative control (Fig. 4B); however, $C D H 1$ mRNA expression was not significantly different in NUGC3 cells transfected with siRNA compared with the negative control group (Fig. 4B).

\section{Discussion}

In the present study, it was revealed that the patients with a high PLS3 expression had a significantly poorer prognosis compared with those with a low PLS3 expression. In addition, $P L S 3$ expression was associated with cancer differentiation, depth of tumour invasion and distant metastasis. Furthermore, it was demonstrated that there was a significant positive association between PLS3 and Vimentin expression in gastric cancer. It was concluded that downregulation of PLS3 in gastric cancer cells was associated with the inhibition of cellular invasion and migration.

The PLS3 gene, located on chromosome Xq23, encodes a protein that functions to polymerize actin fibers through the inhibition of cofilin-mediated actin depolymerization (18); however, there is limited knowledge regarding the biology of PLS3 and its relevance to solid cancer development and progression. A previous study demonstrated that colorectal carcinoma cell lines overexpressing PLS3 acquire invasiveness through the downregulation of E-cadherin (19). Furthermore, supportive evidence that PLS3 may be involved in EMT via TGFB1 stimulation was revealed. In addition, the results of the present study demonstrated that PLS3 is associated with colorectal cancer metastasis and cancer stemness (15). In the present study, it was determined that Vimentin expression is significantly higher in the group with high PLS3 expression than in the low expression group, and the downregulation of $P L S 3$ caused a decrease in the expression of Vimentin mRNA; however, $\mathrm{CDH} 1$ exhibited no significant changes in expression levels between the high and low PLS3 expression groups. Additionally, it was revealed that there was a strong association between PLS3 expression and distant metastasis in gastric cancer. The findings of the present study propose that $P L S 3$ is a key factor in EMT, which in turn leads to regulation of Vimentin. Plastin are a recently described family of actin-binding proteins, which have been implicated in invasion and metastasis (18). The present study provides the first evidence for the clinical significance 

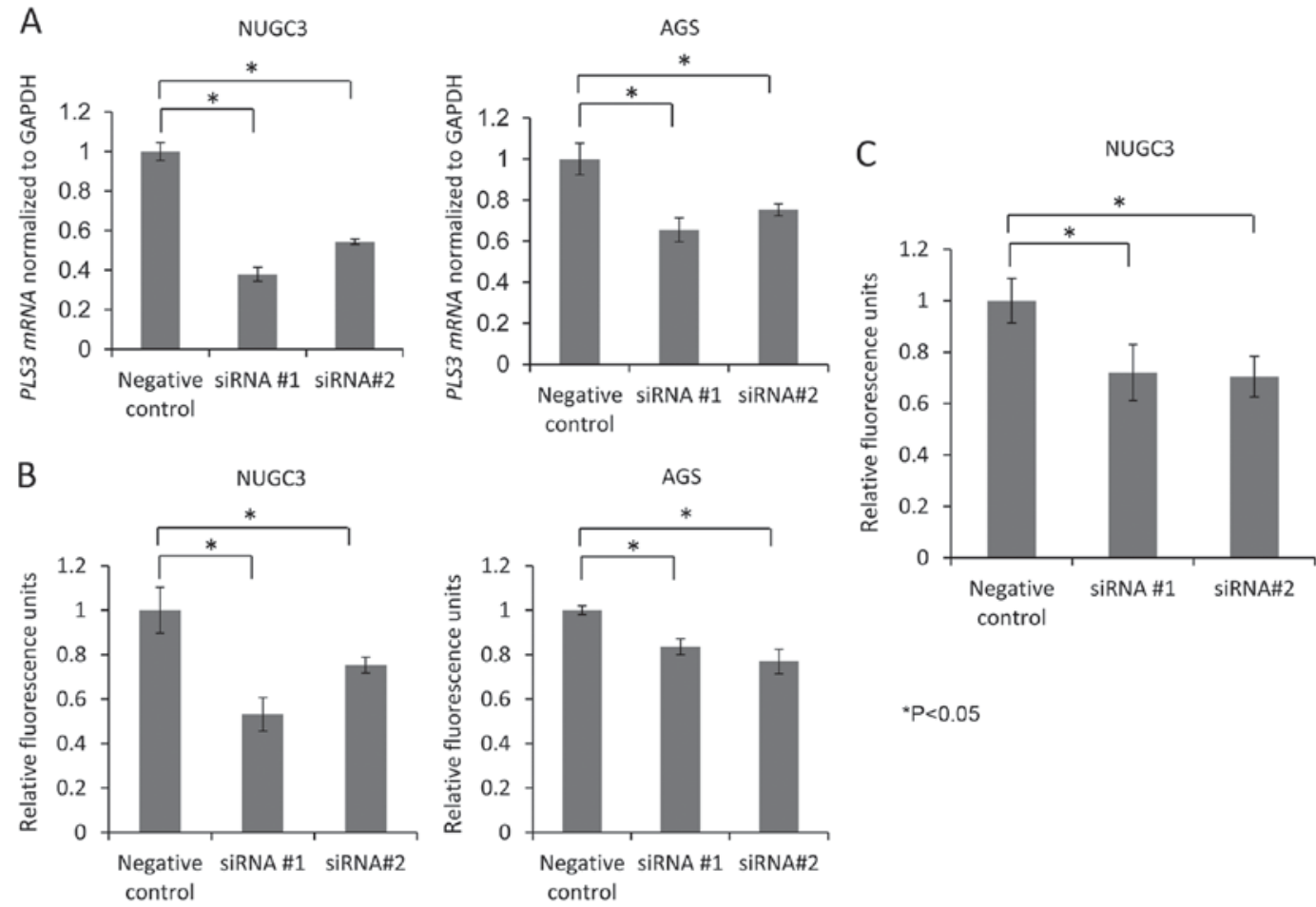

${ }^{*} \mathrm{P}<0.05$

Figure 3. Suppression of PLS3 by siRNA reduced the migration and invasion of gastric cancer cells. (A) PLS3 mRNA expression in NUGC3 and AGS cells transfected with NUGC3 siRNA no. 1 and 2 was measured by reverse transcriptase-quantitative polymerase chain reaction and compared with cells transfected with a negative control siRNA. (B) Migration assays of NUGC3 and AGS cells transfected with PLS3 siRNA, compared with cells transfected with a negative control siRNA. (C) Invasion assays of NUGC3 cells transfected with PLS3 siRNA compared with cells transfected with a negative control siRNA. Each bar represents the mean \pm standard error of the mesan of samples measured in triplicate, and each experiment was repeated $\geq 3$. " $\mathrm{P}<0.05$. PLS3, plastin3; siRNA, small interfering RNA.
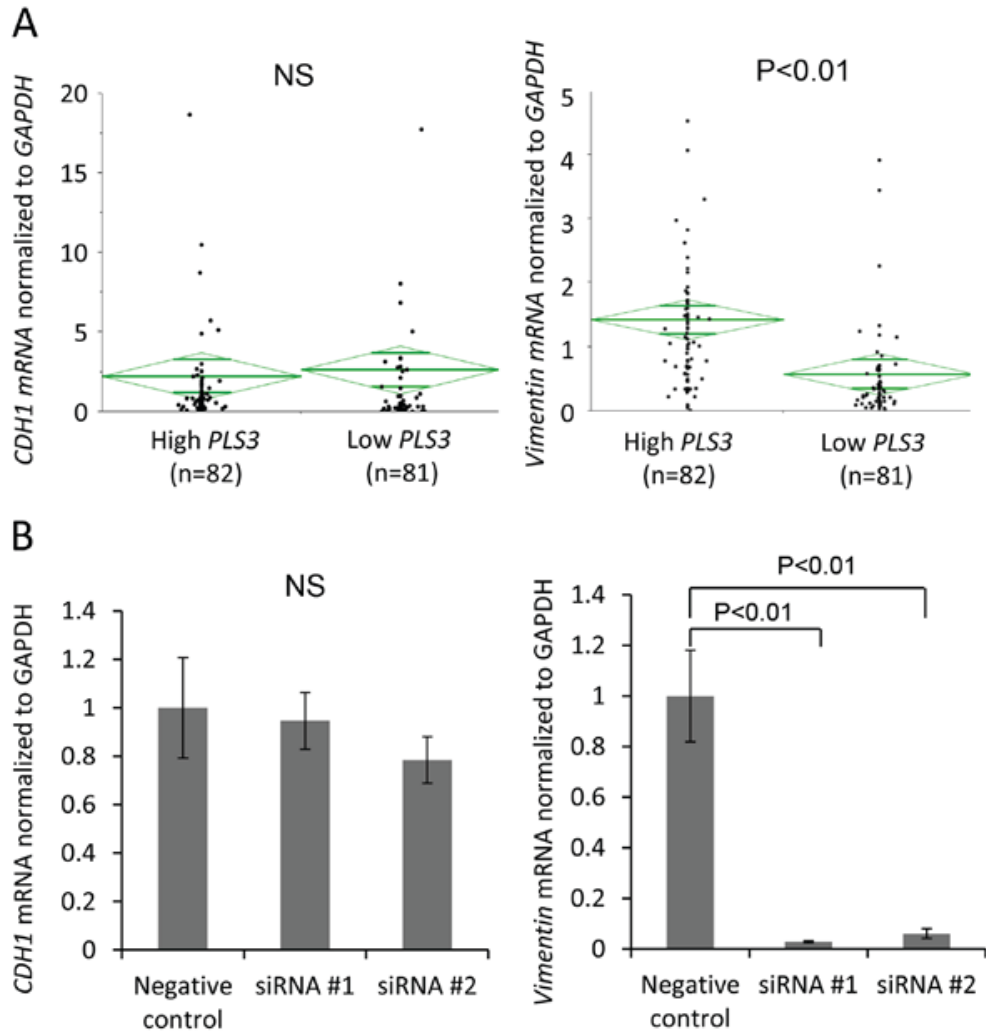

Figure 4. Association of $\mathrm{CDH1}$ and Vimentin expressions with $P L S 3$ expression in gastric cancer. (A) In the high PLS3 expression group (n=82), the expression of Vimentin mRNAs was significantly increased compared with that in the low $P L S 3$ expression group $(\mathrm{n}=81 ; \mathrm{P}<0.01)$. There was no significant difference in $C D H 1$ mRNA expression between the high and low PLS3 expression group. (B) In NUGC3 cells transfected with siRNA PLS3 no. 1 or 2, the expression of Vimentin mRNA was significantly decreased compared with the negative control; however, there was no significant difference in $C D H 1$ mRNA expression between NUGC3 cells transfected with siRNA and the negative control cells. $P L S 3$, plastin3; NS, no significance; siRNA, small interfering RNA; $C D H 1$, Cadherin1. 
of PLS3 in primary gastric cancer. Conversely, the present study identified no significant associations between PLS3 expression and peritoneal dissemination; however, a strong association between PLS3 expression and distant metastasis was determined. Therefore, the results suggest that PLS3 expression may be used in predicting hematogenous metastasis. Furthermore, PLS3 was demonstrated to regulate the invasion and migration in gastric cancer, $P L S 3$-targeted therapy may be more effective in blocking distant metastasis of gastric cancer.

It was reported that the presence of $P L S 3$ in peripheral blood in colorectal cancer cases was significantly associated with disease-free survival and OS time, and PLS3-expressing cells were detected in the peripheral blood of $33 \%$ of Japanese patients with colorectal cancer (15). It was expected that the high PLS3 expression levels in the peripheral blood and bone marrow of patients with advanced gastric cancer could be detected, and therefore the expression of $P L S 3$ in preoperative peripheral blood and bone marrow from the patients with gastric cancer could be investigated; however, there was no significant association between PLS3 expression and cancer staging in the peripheral blood and bone marrow, and there was no significant difference between gastric cancer and healthy volunteers (data not presented). The results in the current study revealed that $P L S 3$ serves an important role in the invasion of gastric cancer cells in primary tumors; however, there was no clinicopathological significance to the presence of the PLS3 gene in the circulation in the gastric cancer cases. This discrepancy may have indicated the differences in hematogenous pathways of cancer progression between colorectal cells and gastric cancer cells. PLS3 is not a useful circulating tumour cell marker in patients with gastric cancer; therefore, the expression of PLS3 in gastric cancer may be lower than in colorectal cancer. A conclusive marker to detect circulating tumor cells has not yet been established for gastric cancer and further studies are required to identify other novel circulating tumour markers of gastric cancer.

In conclusion, the present study demonstrated that high expression levels of $P L S 3$ are independently associated with poor prognosis, and that $P L S 3$ serves an important role in EMT through the inhibition of cellular migration and invasion, and the regulation of Vimentin expression in gastric cancer.

\section{Competing interests}

The authors declare that they have no competing interests.

\section{References}

1. Jemal A, Bray F, Center MM, Ferlay J, Ward E and Forman D: Global cancer statistics. Cancer J Clin 61: 69-90, 2011.

2. Lordick F and Siewert JR: Recent advances in multimodal treatment for gastric cancer: A Review. Gastric Cancer 8: 78-85, 2005.

3. Thiery JP: Epithelial-mesenchymal transitions in tumour progression. Nat Rev Cancer 2: 442-454, 2002.

4. Graziano F, Mandolesi A, Ruzzo A, Bearzi I, Testa E, Arduini F, Silva R, Muretto P, Mari D, Berardi R, et al: Predictive and prognostic role of $\mathrm{E}$-cadherin protein expression in patients with advanced gastric carcinomas treated with palliative chemotherapy. Tumour Biol 25: 106-1010, 2004.
5. Otsuki S, Inokuchi M, Enjoji M, Ishikawa T, Takagi Y, Kato K, Yamada H, Kojima K and Sugihara K: Vimentin expression is associated with decreased survival in gastric cancer. Oncol Rep 25: 1235-1242, 2011.

6. Shin NR, Jeong EH, Choi CI, Moon HJ, Kwon $\mathrm{CH}$, Chu IS, Kim GH, Jeon TY, Kim DH, Lee JH and Park DY: Overexpression of snail is associated with lymph node metastasis and poor prognosis in patients with gastric cancer. BMC Cancer 12: 521, 2012.

7. Liu AN, Zhu Z-HH, Chang SJ and Hang XS: Twist expression associated with the epithelial-mesenchymal transition in gastric cancer. Mol Cell Biochem 367: 195-203, 2012.

8. Okugawa Y, Inoue Y, Tanaka K, Kawamura M, Saigusa S Toiyama Y, Ohi M, Uchida K, Mohri Y and Kusunoki M: Smad interacting protein 1 (SIP1) is associated with peritoneal carcinomatosis in intestinal type gastric cancer. Clin Exp Metastasis 30: 417-429, 2013.

9. Okugawa Y, Toiyama Y, Tanaka K, Matsusita K, Fujikawa H, Saigusa S, Ohi M, Inoue Y, Mohri Y, Uchida K and Kusunoki M: Clinical significance of zinc finger E-box binding homeobox 1 (ZEB1) in human gastric cancer. J Surg Oncol 106: 280-285, 2012.

10. Kosaka Y, Mimori K, Fukagawa T, Ishikawa K, Etoh T, Katai H, Sano T, Watanabe M, Sasako M and Mori M: Clinical significance of molecular detection of matrix metalloproteinase-1 in bone marrow and peripheral blood in patients with gastric cancer. Ann Surg Oncol 19 (Suppl): S430-S437, 2012.

11. Mimori K, Fukagawa T, Kosaka Y, Ishikawa K, Iwatsuki M, Yokobori T, Hirasaki S, Takatsuno Y, Sakashita H, Ishii H, et al: A large-scale study of MT1-MMP as a marker for isolated tumor cells in peripheral blood and bone marrow in gastric cancer cases. Ann Surg Oncol 15: 2934-2942, 2008.

12. Mori M, Mimori K, Shiraishi T, Fujie T, Baba K, Kusumoto H, Haraguchi M, Ueo H and Akiyoshi T: Analysis of MT1-MMP and MMP2 expression in human gastric cancers. Int J Cancer 74: 316-321, 1997.

13. Mimori K, Mori M, Shiraishi T, Fujie T, Baba K, Haraguchi M, Abe R, Ueo $\mathrm{H}$ and Akiyoshi T: Clinical significance of tissue inhibitor of metalloproteinase expression in gastric carcinoma. Br J Cancer 76: 531-536, 1997.

14. Foran E, McWilliam P, Kelleher D, Croke DT and Long A: The leukocyte protein L-plastin induces proliferation, invasion and loss of E-cadherin expression in colon cancer cells. Int J Cancer 118: 2098-20104, 2006.

15. Yokobori T, Iinuma H, Shimamura T, Imoto S, Sugimachi K, Ishii H, Iwatsuki M, Ota D, Ohkuma M, Iwaya T, et al: Plastin3 is a novel marker for circulating tumor cells undergoing the epithelial-mesenchymal transition and is associated with colorectal cancer prognosis. Cancer Res 73: 2059-2069, 2013.

16. Kurashige J, Watanabe M, Iwatsuki M, Kinoshita K, Saito S, Nagai Y, Ishimoto T, Baba Y, Mimori K and Baba H: RPN2 expression predicts response to docetaxel in oesophageal squamous cell carcinoma. Br J Cancer 107: 1233-1238, 2012.

17. Livak KJ and Schmittgen TD: Analysis of relative gene expression data using real-time quantitative PCR and the 2- $\Delta \Delta \mathrm{CT}$ method. Methods 25: 402-408, 2001.

18. Delanote V, Vandekerckhove J and Gettemans J: Plastins: Versatile modulators of actin organization in (patho)physiological cellular processes. Acta Pharmacol Sin 26: 769-779, 2005.

19. Willis ND, Cox TR, Rahman-Casañs SF, Smits K, Przyborski SA, van den Brandt P, van Engeland M, Weijenberg M, Wilson RG, de Bruïne $\mathrm{A}$ and Hutchison CJ: Lamin A/C is a risk biomarker in colorectal cancer. PLoS One 3: e2988, 2008.

20. Edge SB and Compton CC: The american joint committee on cancer: The 7th edition of the AJCC cancer staging manual and the future of TNM. Ann Surg Oncol 17: 1471-1474, 2010.

c) (i) $\Theta$ This work is licensed under a Creative Commons Attribution-NonCommercial-NoDerivatives 4.0 International (CC BY-NC-ND 4.0) License. 